\title{
The research on strategy of effective questioning in junior high school mathematics class
}

\author{
Hongyu Jia ${ }^{\mathrm{a}}$ and Linan Zhong $^{\mathrm{b}}$, $^{\circ}$ \\ Department of mathematics, School of science, Yanbian University, 133000 \\ ajiahongyuaini@qq.com, b'zhonglinan2000@126.com
}

Keywords: Mathematics in junior middle school; effective questioning; core accomplishment of Mathematics

\begin{abstract}
Junior high school mathematics is an important subject of junior high school learning, which has a strong logical thinking. Classroom questioning is an important part of mathematics teaching. The art of teaching lies in how to ask questions appropriately and guide students to answer, which plays an important role in inspiring students' thinking and cultivating core literacy. This paper expounds the problems existing in the mathematics classroom questioning in junior high school and the strategies of effective questioning in the classroom.
\end{abstract}

\section{Introduction}

Albert Einstein once said, "it is more important to ask a question than to solve a problem." Effective questioning can not only improve the teaching efficiency of a class, but also stimulate students' thirst for knowledge, so that students can concentrate highly and think flexibly in effective 40 minutes. Based on the junior middle school students of all ages, there are great differences between psychology and behavior, their thinking during this period, the concept of cognitive learning is not the same, so in the classroom, teachers how to use effective questions, so that students can learn from, in order to discuss, from which efficient classroom is particularly important.

\section{The origin and basic theory of questions}

Ask questions as early as the Warring States period is a kind of teaching method, a famous Chinese educator and thinker Confucius put forward the "heuristic teaching", "mentioned in the Analects bufenbuqi, not determined to learn, do not give a corner to corner against three is not complex also opens the teacher to the student questioning teaching, in Confucius" heuristic teaching for students "after careful consideration to go to the teacher to ask questions, ask the teacher. Socrates Te, a famous educationist and philosopher in the western ancient Greece, came out for the elicitation of teaching.

The research on effective questions mainly originates from the following three theories. First, Piaget's theory of cognitive development, the core of the theory is improved and the conversion process of psychological structure or schema, a question and answer between teachers and students can understand the students inner psychological schema (i.e. knowledge) and does not match the external environment, so as to promote the process of cognitive and intellectual development. Second, the theory of the zone of proximal development is based on the ability gap between children's ability to independently accomplish problems and the ability to complete problems under others' assistance. In the study, each student has the best time "'" learn on their own, teachers should understand the students' learning in the best period, targeted for questioning, the interaction between teachers and students of the external knowledge to the level of development potential, to become proficient in repeated use, until the actual level of development. In order to excavate the potential ability of the students. Third, the theory of multiple intelligences proposed by Howard Gardiner. 
Briefly speaking, each of us has eight main intelligence. In the process of teaching, teachers use multiple intelligences theory to explore gifted students through interaction between teachers and students, and then provide them with suitable opportunities for development.

\section{Problems in mathematics classroom questioning in junior middle school}

The new curriculum standard of mathematics in the nine year compulsory education stage clearly points out that "students are masters of mathematics learning, and teachers are organizers, guides and collaborators of mathematics learning." However, now in the junior middle school mathematics classroom teaching, some teachers can not guide to the role, to grasp the classroom is not enough, the interaction between teachers and students is not skilled, can not grasp the students' thinking, not up to the teaching effect, the students of the class level, the efficiency is low, the teachers' professional knowledge questions with the way and the relevant feedback.

\subsection{The question is lack of gradient and depth}

In the past, to give students a bowl of water, the teacher should have a bucket of water, now it seems that this requirement is not enough, should have a pool of water. Professional knowledge is the basis of teaching. However, the professional knowledge of individual teachers is not strong enough. It will not understand the contents of teaching, nor grasp the connection between vertical and horizontal knowledge. It is difficult to put forward deep questions. At the same time, the difficulty in mathematics classroom teaching is "deep and shallow one foot", without a sense of grads. At the same time, there are also problems raised by teachers, which are lack of variation and extension. And we can not think that in order to improve students' ability to use knowledge and enhance the transformation of problems, we should follow the teaching materials step by step.

\section{2 "base" and "full ask" coexist}

The mathematics classroom teachers, in order to meet the test appraisal or the teaching schedule, the math class from A to $\mathrm{Z}$ as a solo, lack of interaction with the students, this is a "base" course. In order to meet the requirements of the new curriculum reform, some teachers have turned the math class into a "full question". Teachers pay more attention to the number of questions, and do not pay attention to the quality of questions, many problems are vague and out of the mouth. The aimless question is difficult to grasp the heavy and difficult points of the teaching, and it will also confuse the students' thinking.

\section{3 wait for the student to answer the question time short}

According to psychological research, the information of stimulus objects touches the human sensory organs, making the temporary storage need 0.25 -2 seconds, while short-term memory to longer memory takes longer. In the math class, it is important to set up a teacher's cleverly doubt, but a few teachers leave the questions to the students to think after the question, and the time to answer is very short. Pause in the students to the topic, teachers, if asked students to answer or not is not expected to answer, immediately called to ask other students to answer, to no avail, teachers will justify the formation of question and answer mode, and not too much to wait.

\section{4 the strategy of effective questioning in mathematics classroom in junior middle school}

\section{1 create a good atmosphere in the classroom}

Because of the stage of junior high school students' thinking and reasoning ability is not perfect, plus some abstract teaching content, students more exposure will produce a psychological boredom, defiance of the teacher's attention in the classroom, then teachers should interact between teachers and students, put forward to open questions, for example the calculation of $1 / 2+1 / 6+1 / 12+1 / 20+1 / 30$ using a variety of methods the value of this kind of problem will improve the students' activity and can cultivate students' divergent thinking. At the same time, in order to 
create a good atmosphere in the classroom, teachers should modify the questions that they speak and ask for the interest of the students. In solving mathematical problems, do not stick to a fixed pattern or method, be diligent in change, and attract students.

\subsection{The time and space for the students to answer}

Whether it is psychological research, or the effect of "ask questions or answers", teachers should leave time and space for students to answer questions. The object of the question is different, and the reserved time is different. The time for the excellent students to stay is shorter, the time for the middle school stay is a little longer, and the poor students will be able to prolong the time. Teachers should make every student really participate in the study of mathematics classroom, so that effective questions play the most important role. To master the waiting time is an effective way of asking questions in classroom teaching.

\subsection{The question of "quantity" and "degree" in the classroom is moderate, and the time of questioning is seized.}

In the mathematics teaching class, the teacher should grasp the quantity and the degree of the question. The so-called "quantity" is the number of questions. With too many problems and confusion, students' knowledge of heavy and difficult knowledge is often asked. The problem is too few, the boring classroom atmosphere is not loved by the students, and the learning effect is not good. The so-called "degree" is the difficulty of the problem. Avoid "right" in teaching? "Is it?" This kind of simple problem does not make any sense. Nor do we need to put forward difficult questions for students to fight against students' enthusiasm. A real good classroom is not only for students to learn, but also for students to learn. In the course of explaining the content of mathematics, teachers should seize the appropriate amount and moderate questions, but also seize the opportunity of questioning. In this section, the difficult and difficult place to set up questions and answers will allow students to understand the contents faster and better, and use their knowledge to make the results twice the result with half the effort. Also it is more wonderful a pen, let the teacher not only to seize the classroom, but also to seize the students.

\subsection{Pay attention to the feedback of students' questions}

Teachers should not interrupt students when they answer questions, so that students can finish all the answers. After the answer is finished, teachers should evaluate students in time. Teachers should reflect on the answers answered by students and make them an important resource for class. According to the feedback of the classroom to assess the effect of teaching, timely and effective adjustment of their teaching strategies and teaching methods and teaching progress. American psychologist Bruba believes that "the highest principle of the most exquisite teaching art is to ask students to ask questions." The number of students' feedback will be challenged with questions, and teachers' understanding of knowledge is not clear. Teachers should carefully study and answer students' misunderstanding points and blind spots. The feedback of students is also the key link of effective questioning. It pays attention to the feedback of students and brings positive effects to the whole teaching process.

\section{Through effective questioning, the students' core quality of mathematics is cultivated.}

In the the fifth Plenary Session of the 18th CPC Central Committee, the reform of education was put forward, and the core literacy came to the fore from the education expert's mouth. Mathematics core literacy is based on knowledge and skills, but higher than knowledge and skills. The core competency of mathematics can be understood as the specific ability of students to learn mathematics. Abstract mathematics, logic reasoning, mathematical modeling, mathematical calculation, visualization, data analysis covers six aspects of core competence and basic 
mathematics, mathematics thought and mathematics ability is also the summary of effective questioning in the mathematics classroom on the development of students' thinking, students also learn the origin of the formation of mathematical ability.

Whether in the compulsory education mathematics curriculum standard (2011 Edition), the "double base" is upgraded to the "four basis" or the core quality is put forward, all of which emphasize the cultivation of students' thinking. In a high - quality class, classroom questioning is the best way to stimulate students' potential, improve their abilities and create students' ideas. Abstract thinking is the mathematics thought, by asking questions to lead students into the mathematical relationship between the number of changes of environment, and feelings of mathematics; the premise is the question whether reasoning, deductive reasoning and plausible reasoning, can be determined by the teacher in the teaching in the right node in question and answer the students, to guide students to use inductive reasoning the mathematical results, at the same time, can also be used to verify the mathematical deduction results based reasoning; questioning is model of thought, teaching by the way of understanding the students understanding of mathematical concepts, principle and method, so as to help the students to describe a class of problems to solve real world, depict a kind of model of things. The traditional mathematics ability is sublimated under the teacher's question, making the students master the strong mathematical ability.

When one is learning mathematics, even if this person does not work in Mathematics in the future, he should observe the world with mathematical eyes, analyze the world with mathematical thinking, and express time in mathematical language. This is the essence of mathematics, and it is also the significance of cultivating the students' core literacy through effective questioning in the classroom.

\section{Summary}

The questions on the teaching class are the important branches of the teaching process, the focus of the teaching design and the outstanding performance of the teaching behavior. Effective questioning is the key to opening students' interest in learning and developing students' thinking. But whether the teachers can raise valid questions, whether can improve the effectiveness of classroom questioning, whether it can effectively stop, whether can effective feedback, whether it can effectively reflect, whether can master a class, should be a course as an educator must do.

\section{References}

[1] Ju Ming Deng. An analysis of effective questions in the teaching of mathematics in junior middle school [J]. good parents, 2017, (30): 139.

[2] Xueyu Zhao. The strategy of effective questioning by teachers in mathematics classroom teaching in junior middle school [J]. mathematics study and research, 2017, (11): 61.

[3] Xi Wei. An elementary introduction to the effective questioning strategy of mathematics class in junior middle school under the new course [J]. Chinese school education, 2017, (13): 94-95.

[4] Lijun Qiao. Core literacy for the basic premise and important value, cultivate the mission [J]. Journal of Hebei Normal University (SOCIAL SCIENCE EDITION), 2016,18 (05): 114-118.

[5] Chunyu Liu. A summary of the research on the core literacy of mathematics in China, [J]. education and teaching forum, 2017, (41): 117-118.

[6] Hui Wei. Asking questions in clever classroom to promote teaching effectiveness -- effective questioning strategies in junior high school science classroom [J]. Journal of Shanxi Normal University (NATURAL SCIENCE EDITION), 2011,25 (S1): 107-108. 